\title{
Impact of maximum sustainable yield-based fisheries management frameworks on rebuilding North Atlantic cod stocks
}

\author{
Peter A. Shelton and M. Joanne Morgan \\ Science Branch, Department of Fisheries and Oceans, P. O Box 5667, \\ St. John's, NL, A1C 5X1, Canada \\ Email: Peter.Shelton@dfo-mpo.gc.ca
}

\begin{abstract}
SHELTON, P. A., and M. J. MORGAN. 2014. Impact of maximum sustainable yield-based fisheries management frameworks on rebuilding North Atlantic cod stocks. J. Northw. Atl. Fish. Sci., 46: 15-25. doi:10.2960/J.v46.m697
\end{abstract}

\begin{abstract}
Fisheries management frameworks based on maximum sustainable yield reference points have been put forward by all agencies and organizations responsible for providing scientific advice for the management of 22 major North Atlantic cod stocks. These frameworks provide a structure for rebuilding depleted cod stocks and for future sustainable fishing. Unfortunately, in most cases these frameworks have not been fully implemented. Although information is lacking for some stocks, it would appear that a large proportion of North Atlantic cod stocks are either experiencing a fishing mortality rate that exceeds that required to achieve maximum sustainable yield, are at a biomass level far below that which provides maximum sustainable yield, or have both occurring. Despite this general failure, there are some notable successes, which have led to stock rebuilding and substantial fisheries, providing an incentive for striving to achieve rebuilding and sustainable management objectives for other Atlantic cod stocks. Management frameworks based on harvest control rules that result in fishing mortality rates below those associated with maximum sustainable yield are essential when stock size is low in order to rebuild to levels capable of producing maximum sustainable yield.
\end{abstract}

Keywords: Atlantic cod, depleted fish stocks, stock rebuilding, overfishing, MSY-based management frameworks, rebuilding plans, management plans, feedback harvest control rules.

(C) Her Majesty the Queen in right of Canada, 2014.

\section{Introduction}

The need to adopt a Precautionary Approach to fisheries management in order to avoid serious harm to fish stocks was firmly established by the UN Fish Stock Agreement (UNFSA; UN, 1995). This led to a focus on estimating and avoiding Limit Reference Points for spawning stock biomass $(S S B)$ and fishing mortality $(F)$. Following UNFSA, rebuilding already depleted fish stocks and the sustainable management of healthy stocks received emphasis at the World Summit on Sustainable Development (WSSD) in Johannesburg (UN, 2002). The accord calls for actions to "Maintain or restore stocks to levels that can produce the maximum sustainable yield with the aim of achieving these goals for depleted stocks on an urgent basis and where possible not later than 2015". The focus thus shifted from avoiding limits under UNFSA to achieving maximum sustainable yield (MSY) targets under WSSD. Although 2015 is proving an ambitious goal for rebuilding to the SSB associated with maximum sustainable yield $\left(S S B_{\text {msy }}\right)$, the WSSD continues to influence approaches to fisheries management in a number of positive ways.

In Europe, the decision by the European Commission to implement the maximum sustainable yield (MSY) principle led ICES to introduce a new MSY-based approach for providing advice in 2009 (Lassen et al., 2013). In the US, the 2006 Reauthorization of the Magnuson-Stevens Fishery Conservation and Management Act (MSFCMA) emphasized an MSY-based approach that requires overfishing to stop and for depleted stocks to be rebuilt (NOAA, 2007). In Canada, new MSY-based fisheries policies were developed under the Sustainable Fisheries Framework (SFF; DFO, 2009a). In 2008 the Northwest Atlantic Fisheries Organization expanded its Convention to include MSY-based objectives (NAFO, 2008).

These policy changes are beginning to have a positive effect, although, in the case of several important Atlantic 
cod (Gadus morhua) stocks, full development of MSYbased frameworks including harvest control rules, and effective implementation, is lagging policy development. In this paper MSY-based fisheries frameworks are compared across advisory bodies (International Council for Exploration of the Sea (ICES), Canadian Department of Fisheries and Oceans (DFO), Northwest Atlantic Fisheries Organization (NAFO), US National Oceanic and Atmospheric Administration National Marine Fisheries Service (NOAA-NMFS)). A summary is provided on progress in completing these frameworks and applying them to rebuild Atlantic cod stocks. Conclusions are drawn regarding what needs to be done to make these frameworks fully operational and to achieve success in rebuilding cod stocks.

\section{Comparison of MSY-based advisory frameworks}

There are a number of similarities across MSY-based advisory frameworks applied by the various bodies providing scientific advice for the management of fisheries on Atlantic cod stocks, but there are also some important differences. The ICES MSY-based framework (Fig. 1) is designed to promote recovery of a stock to the normal range of stock sizes associated with MSY when $S S B$ is below this range, i.e. when it is below $S_{S} B_{\text {trigger }}$ (Lassen et al., 2013). Below $S S B_{\text {trigger, }}$ the advised fishing mortality $(F)$ is reduced from the fishing mortality that gives MSY $\left(F_{\text {msy }}\right)$ by a linear function. When the stock size is so low that recruitment failure is a concern, e.g. at or below an $S S B$ limit reference point $S S B_{\text {lim }}$, as estimated for a Precautionary Approach (PA), additional conservation measures may be invoked to prevent a further decline. It should be noted that under the ICES approach, $F_{\text {msy }}$ is currently considered a target exploitation rate but once this is achieved for most stocks, ICES may consider whether the fishing mortality target should be adjusted to be less than $F_{\text {msy }}$ (Lassen et al., 2013).

The Canadian MSY-based framework (Fig. 2) recognizes three SSB zones, Healthy, Cautious and Critical (DFO, 2009a). In the Healthy Zone fishing morality may be set at a level of $F_{\text {msy }}$ or lower. Once $S S B$ falls below the lower boundary of the Healthy Zone, termed the Upper Stock Reference Point, and enters the Cautious Zone, fishing mortality must be reduced to return the stock to the Healthy Zone. If SSB falls below the Limit Reference Point and enters the Critical Zone, fishing mortality from all sources must be kept to an absolute minimum. A provisional harvest control rule (HCR) based on this is approach defines the Upper Stock Reference Point to be $80 \% S S B_{\text {msy }}$, the Limit Reference Point to be $40 \% S S B_{\text {msy }}$ and the decrease in fishing mortality to be linear, reaching zero at $40 \% S S B_{\text {msy }}(\mathrm{DFO}, 2009 \mathrm{a})$. The

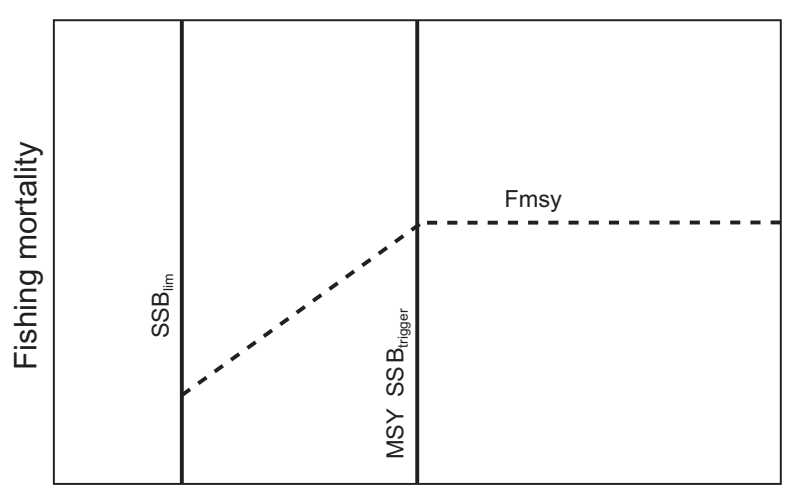

Spawning stock biomass

Fig. 1. MSY-based framework adopted by ICES for providing scientific advice. The broken line indicates the fishing mortality rate that would be advised depending on the spawning stock biomass. Below $S S B_{\lim }$ additional conservation measures may be invoked based on the Precautionary Approach.

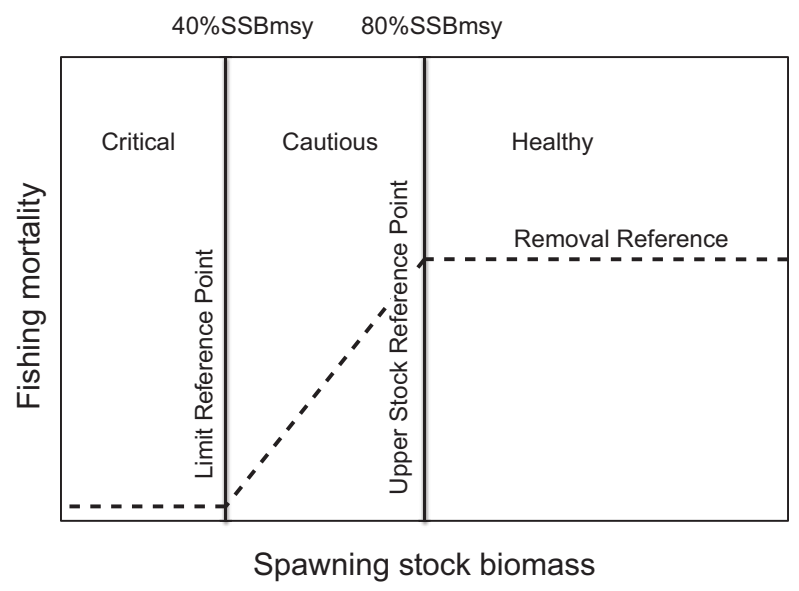

Fig. 2. MSY-based framework adopted by Canada for providing advice on Canadian fish stocks. Vertical lines demarcate spawning stock biomass zones. The broken line indicates the fishing mortality to be advised. In the Healthy Zone the removal reference mortality rate can be set at $F_{\text {msy }}$ or lower.

Canadian framework is ambiguous with regard to whether $F_{\text {msy }}$ should be considered a target or a limit since fishing mortality can be set as high as $F_{\text {msy }}$ in the Healthy Zone.

The NAFO Precautionary Approach Framework (NAFO, 2004a), augmented by the 2008 NAFO Resolution on the Interpretation and Implementation of the Convention on the Future Multilateral Cooperation in the Northwest Atlantic Fisheries (NAFO, 2008), provides an MSY-based context for scientific advice. The 2008 Resolution requires that NAFO adopt measures based on the best scientific 
evidence available to ensure that fishery resources are maintained at, or restored to, levels capable of producing MSY. The NAFO PA framework recognizes five zones based on SSB and F: Safe, Overfishing, Cautionary $F$, Danger and Collapse (Fig. 3). In the Safe Zone, i.e. when $S S B>S S B_{\text {buf }}, F$ must be selected to have a low probability $(<20 \%)$ of exceeding a fishing mortality limit reference point $F_{\text {lim }}$, which is defined by NAFO as $F_{\text {msy }}$, and a very low $(<10 \%)$ probability of being below $S S B_{\text {lim }}$ which has a default value of $30 \% S S B_{\text {msy }}$ unless defined on some other basis in order to take into account specific stock-recruit considerations (NAFO, 2004b). In the Overfishing Zone $F$ needs to be set below a fishing mortality "buffer" level, $F_{\text {buf }} . F_{\text {buf }}$ should be specified by managers and should satisfy the requirement that there is a low probability $(<20 \%)$ that any fishing mortality rate estimated to be below $F_{\text {buf }}$ will actually be above $F_{\text {lim }}$. In the Cautionary $F$ Zone, the closer $S S B$ is to $S S B_{\text {lim }}$, the lower $F$ should be below $F_{\text {buf }}$ to ensure that there is a very low $(<10 \%)$ probability that biomass will decline below $S S B_{\text {lim }}$ within 5-10 years. The NAFO framework allows for buffer reference points to be superseded by computations of the risk of being below $S S B_{\text {lim }}$ or above $F_{\lim }$ and for managers to set risk tolerances other than the default values specified above.

Under the US MSFCMA MSY-based framework, four zones are recognized (NOAA, 2007; Fig. 4): (i) Overfishing is not occurring, stock is not Overfished; (ii) Overfishing is occurring, stock is not Overfished; (iii) Overfishing is occurring, stock is Overfished; (iv) Overfishing is not occurring, stock is Overfished. Overfishing is defined as $F \geq F_{\text {msy }}$ and Overfished as $S S B<50 \% S S B_{\text {msy }}$. If a stock is identified as being Overfished, Overfishing has to end within two years. Further, Overfished stocks are required to be subject to a rebuilding plan that will rebuild the stock to $S S B_{\text {msy }}$ within a specified period of time, typically not exceeding 10 years, by reducing $F$. Further, $F$ is required to be adjusted to prevent Overfishing from occurring whenever a stock is identified to be approaching an Overfished condition. Given that Overfishing is considered to be $F \geq F_{\text {msy }}$, the US MSY-based approach considers $F_{\text {msy }}$ as a limit.

It is clear from this comparison of MSY-based approaches currently being applied to Atlantic cod stocks that the interpretation of $F_{\text {msy }}$ in terms of whether it constitutes a limit or a target varies, although none of the approaches support deliberately setting $F>F_{\text {msy }}$. It should be noted that if $F_{\text {msy }}$ is considered to be a limit to be avoided with a probability $>50 \%$, then there is an apparent contradiction in simultaneously considering $S S B_{\text {msy }}$ to be a target with the consequent expectation that it would be achieved with

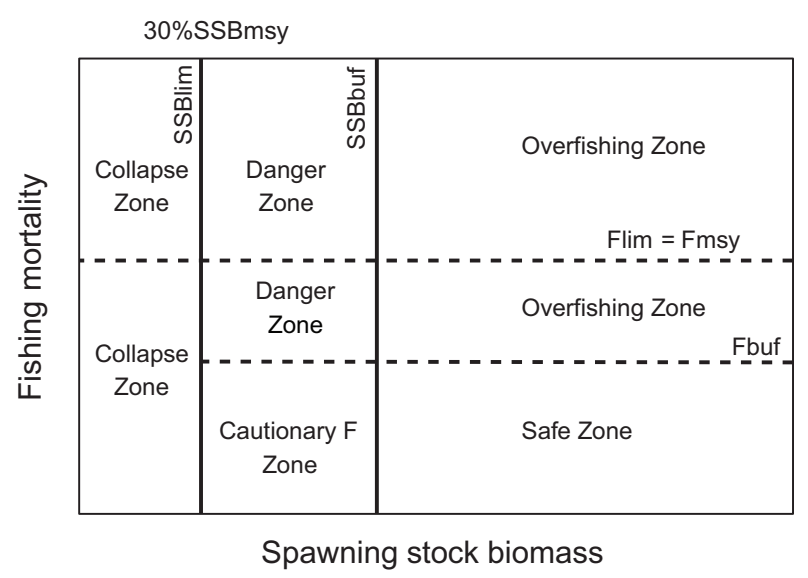

Fig. 3. MSY-based framework adopted by NAFO for advising on stocks in the NAFO Regulatory Area. Vertical solid lines demarcate spawning stock biomass zones whereas broken horizontal lines demarcate fishing mortality zones.

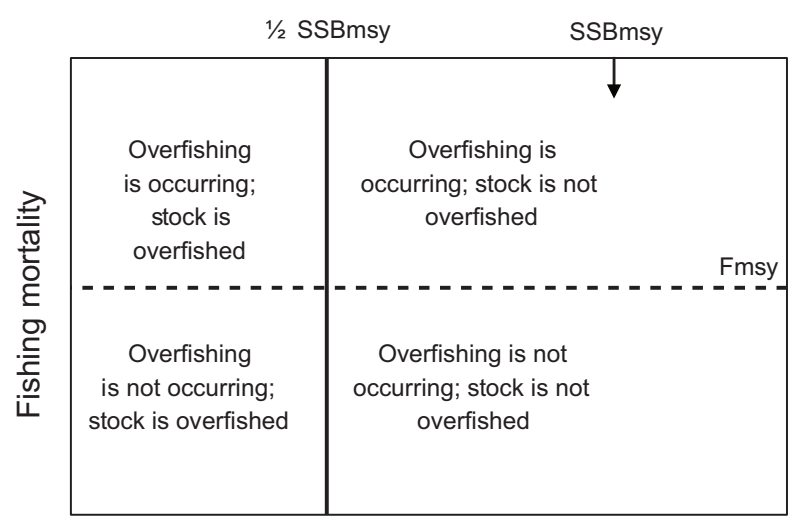

Fig. 4. MSY-based framework adopted by the US National Marine Fisheries Service for providing scientific advice under the MSFCMA. The vertical solid line demarcates spawning stock biomass zones whereas the horizontal broken line shows $F_{\text {msy. }}$

a 50\% probability (i.e. a risk-neutral desired outcome in keeping with the definition of a target).

All the MSY-based frameworks require $F$ to be reduced below $F_{\text {msy }}$ to rebuild the stock should biomass fall below an $S S B$ level specified in the framework, denoted generically as $S S B_{\text {ref }}$ in this paper. The actual derivation of $S S B_{\text {ref }}$ varies across frameworks and is discussed further below. The Canadian framework proposes a specific provisional HCR for achieving the reduction in $F$ below $S S B_{\text {ref }}$. The NAFO framework emphasizes risk tolerances that need to be met with respect to avoiding limit reference points when adjusting $F$ in each zone. The US framework 
emphasizes rapid cessation of Overfishing through $F$ reduction below $F_{\text {msy }}$ to achieve a 10 year or less time

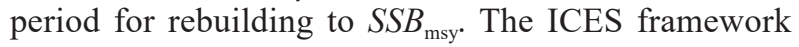
typically advises a linear reduction in $F$ as $S S B$ decreases below $S S B_{\text {ref. }}$

\section{Application of MSY-based frameworks to Atlantic cod stocks}

Information on the scientific assessments and advice for 22 major Atlantic cod stocks are readily available from the websites of the advisory bodies of the responsible organizations (Table 1). ICES provides advice for 11 of these cod stocks, Canada (DFO) for 7, while NAFO and the US (NOAA - NMFS) provide advice for 2 stocks each.

A state-space assessment model (SAM; unpublished; Anders Nielsen, DTU AQUA, National Institute of Aquatic Resources, Section for Marine Living Resources, Technical University of Denmark, Charlottenlund Slot Jægersborg Allé 1, 2920 Charlottenlund, Denmark), is currently applied to 5 of the 11 Atlantic cod stocks for which ICES provides advice. Methods used on other cod stocks include Extended Survivors Analysis (XSA; Darby and Flatman, 1994; Shepherd, 1999), Sequential Population Analysis (ADAPT version; Gavaris, 1988), Statistical Catch at Age (SCAA; Fournier and Archibald, 1982), Survey Based Analysis (SURBA; Beare et al., 2005), Time Series Analysis (TSA; Gudmundsson, 1994) and Age Structured Assessment Program (ASAP; NEFSC, 2013b). Two stocks are assessed qualitatively while two stocks have no method applied because of low abundance. Although a comparison of the strengths of these assessment approaches is beyond the scope of this paper, it should be noted that the SURBA approach uses only survey data and therefore has limited value in terms of MSY-based TAC (total allowable catch) management.

The $S S B$ level below which $F$ should be reduced, $S S B_{\text {ref, }}$ (for example MSY $S S B_{\text {trigger }}$ under ICES) is undefined for all Canadian and NAFO stocks, as well as for three ICES stocks. $S S B_{\text {ref }}$ is not required under NAFO when risk with respect to limit reference points can be reliably estimated. For five of the ICES stocks, $S S B_{\text {ref }}$ is based on the precautionary $S S B, B_{\mathrm{pa}}$, which is computed as $1.4 * S S B_{\text {lim }}$ for three of the stocks and as the level below which recruitment is impaired for two stocks. For Barents Sea cod $S S B_{\text {ref }}$ is denoted as the lowest $S S B$ estimate having $>90 \%$ probability of being above $S S B_{\text {lim }}$. A similar approach is applied to West of Scotland cod.

The approach for determining TAC advice to achieve an $F$ reduction when the stock declines below $S S B_{\text {ref }}$ varies across advisory bodies and cod stocks. In some cases the change in $F$ is governed by a feedback harvest control rule (HCR), which alters $F$ in response to the estimated $S S B$ from the stock assessment relative to the estimated $S S B_{\text {ref }}$, for example $S S B_{\text {trigger }}$ Examples include advice from ICES on Barents Sea cod and Icelandic cod (ICES, 2013). A feedback HCR is also encompassed in the DFO management framework (DFO, 2009a) although implementation in providing advice on Canadian cod stocks has not yet materialized. NAFO advice is not based on a prescribed HCR and instead outcomes from a range of $F$ options are provided (see for example $3 \mathrm{M}$ cod advice; NAFO, 2013). DFO advice for 3Ps cod is also based on providing the outcome of $F$ options to managers (DFO, 2012a). The Northeast Fisheries Science Center of the US National Marine Fisheries Service (NEFSC) advice for the depleted Gulf of Maine and Georges Bank cod stocks are based on $75 \% F_{\text {msy }}$ with the expectation from model projections that this will rebuild stocks to $S S B_{\text {msy }}$ within the requisite 10 year time period (NEFSC, 2013a). In some cases where $F$ is currently well above $F_{\text {msy, }}$ stepwise reductions in $F$ towards $F_{\text {msy }}$ have been instituted (e.g. Baltic cod stocks).

Although there is uncertainty in the assessed state of the stock and in the estimates of MSY reference points, advice for Atlantic cod stocks tends to be based on the point estimate or median estimate of $S S B$ from the current assessment relative to the best estimate of $S S B_{\text {ref }}$. In some cases, such as Icelandic cod, the HCR within the Management Plan has been evaluated with respect to uncertainty through simulation testing by applying management strategy evaluation (MSE; De Oliveira et al., 2008), and found to conform with the ICES MSY approach (ICES, 2009). The Canadian provisional HCR based on an $S S B_{\text {ref }}$ of $80 \% S S B_{\text {msy }}$ and $S S B_{\text {lim }}$ of $40 \% S S B_{\text {msy }}$ has yet to be subject to an evaluation of robustness to uncertainty through simulation testing.

All organizations providing scientific advice on Atlantic cod stocks develop that advice through a consensusforming approach. This has recently become an issue in the US advisory system with regard to a contested assessment for Gulf of Maine cod where industry-hired consultants presented an alternative, more optimistic analysis for consideration as part of the NMFS process for developing scientific advice for managers (Butterworth and Rademeyer, 2008a, MS 2008b). While contested assessments are not necessarily bad (see for example Starr et al., 1998), they create a more complex dynamic and create a dilemma if consensus cannot be reached. In most cases stock assessments are based on a prior benchmark review to establish the best assessment model, which is then applied to new data on an annual basis to provide scientific advice, until a better assessment model is 
SHELTON and MORGAN: Impact of fisheries management on rebuilding North Atlantic cod stocks

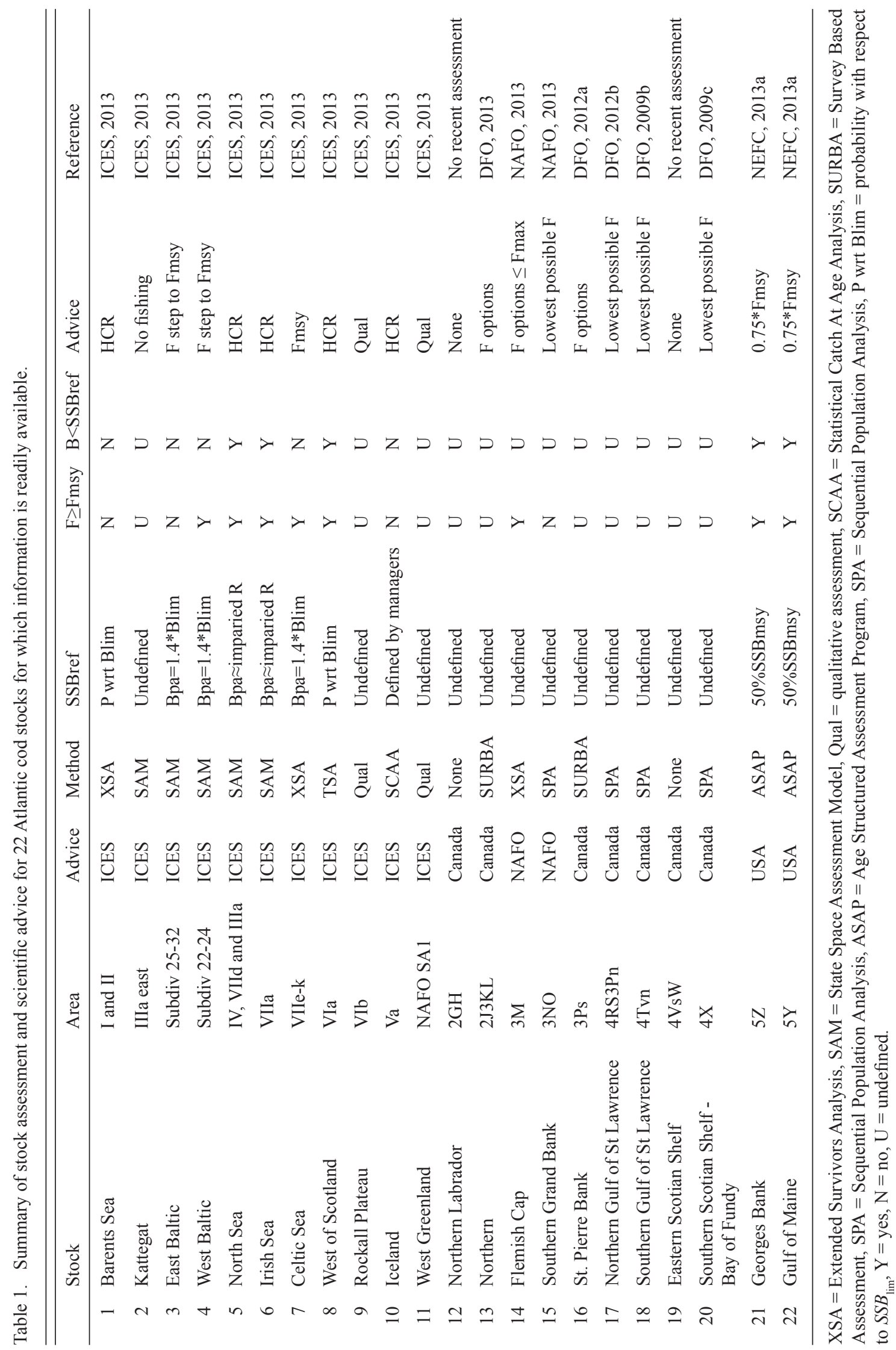


proposed and accepted. Contested assessments generally introduce changes to the current assessment model, for example a domed shaped selectivity function rather than a flat-topped function (Butterworth and Rademeyer, 2008a, MS 2008b), requiring a new benchmark review. If the review cannot resolve the best model to apply, then this may result in two different sets of advice being provided to managers, which may be confusing. Model uncertainty is important if it leads to substantially different estimates of MSY reference points and the status of the stock relative to these reference points, and therefore shouldn't be ignored. If there is no consensus on the best model, an alternative to model-averaging or integrating over the risk estimated by both models, is to evaluate the robustness of a feedback HCR to both models through MSE, to ensure that the objectives are achieved irrespective of which model is closer to reality (De Oliveira et al., 2008).

\section{Response of Atlantic cod stocks to MSY-based management}

Total landings of Atlantic cod from all stocks peaked at around 4 million tons in the late 1960s, declined steadily during the 1970s, 1980s and early 1990s, stabilized below one million tons in the 2000s, and then increased slightly in the most recent years (FAO, 2013; Fig. 5). Trajectories were similar for the North East Atlantic stocks and the North West Atlantic stocks up until 1990 after which the North West Atlantic cod fisheries collapsed and subsequently failed to rebuild. In comparison, North East Atlantic cod landings leveled off during the 2000s and since 2008 have shown a modest increase, which may be related to implementation of HCRs based on MSY

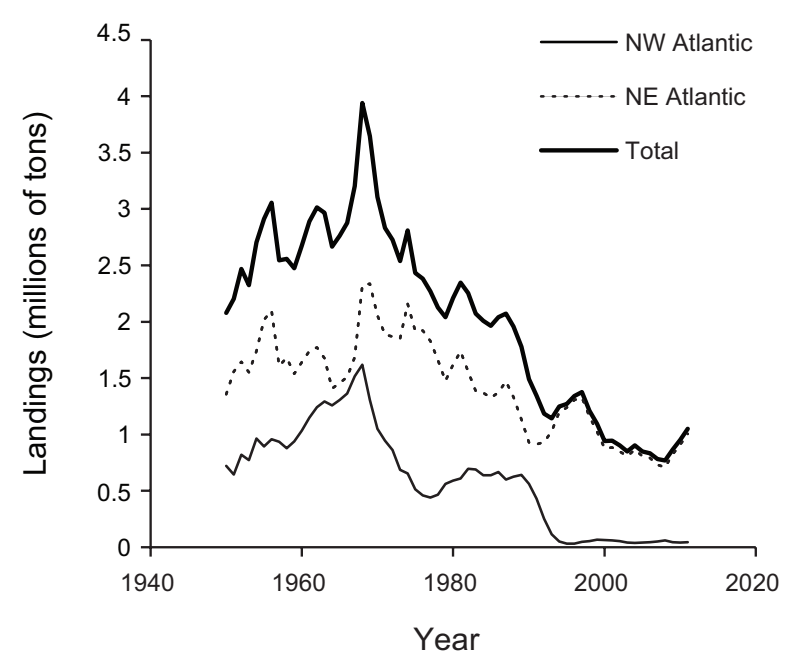

Fig. 5. Total landings of cod from the North Atlantic and for the North East and North West Atlantic separately. Data are from the 2013 edition of FAO Fishery Statistical Collections Global Capture Production. frameworks. The recent trends in North East Atlantic cod are driven mainly by the Barents Sea and Iceland stocks, which historically did not suffer the same level of depletion from overfishing as many other cod stocks, particularly those in the North West Atlantic.

Information on 22 major Atlantic cod stocks summarized in Table 1 can be used to determine whether or not an $S S B_{\text {ref }}$ value has been set for the stock and whether or not an HCR is in place to adjust $F$ when $S S B$ falls below $S S B_{\text {ref- }}$. Adopting terms used in the US under the MSFCMA, for those stocks for which the required information is available, one can evaluate whether Overfishing is taking place $\left(F \geq F_{\text {msy }}\right)$ or whether the stock is Overfished $\left(S S B<S S B_{\text {ref }}\right.$ ). For 10 of the 22 stocks (45\%), Overfishing could not be evaluated because there is no recent assessment, no estimate of current $F$, or no estimate of $F_{\text {msy }}$ Of the remaining 12 stocks, $8(66 \%)$ have Overfishing taking place. With regard to being Overfished, this could be determined for 10 of the 22 stocks $(45 \%)$. For four of these $(40 \%)$ the stocks are Overfished and also have Overfishing taking place. If it is assumed that for all stocks for which Overfished status is unknown, the stock is in fact Overfished, with the exception of Flemish Cap cod for which $S S B$ is currently estimated to be high relative to historic values (NAFO, 2013), then the percentage of Overfished cod stocks rises to $64 \%$. Only 5 of the 22 stocks $(23 \%)$ are known not to have Overfishing taking place.

For 12 of the 22 stocks (55\%) $S S B_{\text {ref }}$ has not yet been determined. Full feedback HCRs are developed for only 5 of the 22 stocks (23\%). For 12 other stocks a range of $F$-based advice is provided that does not involve adjusting the level of $F$ based on current $S S B$ relative to $S S B_{\text {ref }}$. Only three cod stocks are known to be neither Overfished nor subject to Overfishing - Barents Sea cod, Icelandic cod and East Baltic cod. Assessments for these stocks are carried out in ICES scientific working groups and advice is provided through the ICES advisory process (ICES, 2013). A common factor for these three stocks has been a steady decrease in $F$ over the last decade or more. In the case of Barents Sea and Icelandic cod, feedback HCRs have been implemented that set $F_{\text {msy }}$ as a target fishing mortality and reduce $F$ below $F_{\text {msy }}$ when the stock falls below $S S B_{\text {trigger }}$ (ICES, 2013).

\section{Discussion}

Although conceptual MSY-based frameworks are now in place for all Atlantic cod stocks, the parameterization of these frameworks (determination of all required reference points and the explicit mathematical form of the feedback HCR), as well as actual implementation on the fishery, is lagging in a number of cases. Consequently it may be 
premature to expect positive effects from MSY-based frameworks for many of these stocks. This is particularly true for North West Atlantic cod stocks, where little or no recovery has taken place since the adoption of MSYbased approaches as indicated by the consistently low total landings trend. Most cod stocks assessed by Canada and NAFO lack estimates of $F_{\text {msy }}$ and $S S B_{\text {ref. }}$. Two of the stocks assessed by Canada, Northern cod and St. Pierre Bank cod, are assessed using only survey data because commercial and recreational catch statistics are considered unreliable (DFO, 2012a, 2013). Consequently application of the MSY-based approach on these stocks is not possible.

Two cod stocks assessed by Canada have no recent assessments because of ongoing low stock size. Only one cod fishery managed by either Canada or NAFO is known not to have Overfishing taking place (Southern Grand Bank cod), although this stock is Overfished because $S S B$ is below $B_{\text {lim }}$ (NAFO, 2013). In the recent past it was concluded that bycatch mortality was a major factor delaying recovery of this stock (Shelton and Morgan, 2005). Only two North West Atlantic cod stocks have significant directed commercial fisheries at present, St. Pierre Bank cod and Flemish Cap cod. If the $F$ that gives maximum yield per recruit, $F_{\max }$, is taken as a proxy for $F_{\text {msy }}$ then with current $F>2 * F_{\text {max }}$ (NAFO, 2013), the Flemish Cap cod stock has Overfishing taking place. The SURBA-based assessment of St. Pierre Bank cod indicates high total mortality rates on this stock but there is no estimate of $S S B_{\text {ref }}$ (DFO, 2012a). Consequently, neither St. Pierre Bank cod fishery nor Flemish Cap cod fishery can currently be considered sustainably managed at the present time (not Overfished, Overfishing not taking place) under their respective MSY-based frameworks.

Flemish Cap cod is unique among North West Atlantic cod stocks in that it has had a recent rapid and substantial increase in SSB (González-Troncoso et al., MS 2013). This stock was placed under a fishing moratorium between 1999 and 2009 following stock collapse. SSB increased after 2006 as a result of good recruitment and low fishing mortality, reaching highest recorded $S S B$ levels since the start of the series in 1972 by 2012, well above $S S B_{\text {lim }}$. However, the absence of a fully parameterized MSYbased framework and implementation error with respect to the current scientific advice has resulted in $F$ once again increasing and the stock is currently subject to Overfishing (NAFO, 2013). Consequently the expectation is that this stock will decline and that ongoing sustainable management of the fishery will not be achieved.

The failure of most Canadian and NAFO managed cod stocks to rebuild can be attributed in large part to ongoing fisheries, either directed or bycatch, removing all or nearly all the surplus production (Shelton et al., 2006). Directed fishing is allowed on several Canadian stocks despite $S S B$ being well below $S S B_{\text {lim }}$, resulting in levels of $F$ that are not conducive to stock recovery. There is no explicit rebuilding plan in place for most of these stocks, providing targets and timelines, and fisheries management decisions are made largely on an ad hoc basis. In some cases surplus production is very low or negative, leading to pessimistic prognoses regarding possible rebuilding even in the absence of fishing (e.g Southern Gulf Cod; Swain and Chouinard, 2008).

Although US fisheries policy has been considerably strengthened through the reauthorization of the MSFCMA in 2006, the Gulf of Maine and Georges Bank cod fisheries remain Overfished and have Overfishing taking place (NEFSC, 2013a). In comparison there has been more success with regard to rebuilding other US fish stocks. Of the 85 fish stocks or stock complexes declared Overfished under the MSFCMA, rebuilding plans were implemented for 79 , of which 25 were classified as rebuilt to $S S B_{\text {msy }}$ by September 2012 (five additional stocks were rebuilt before a plan was implemented; NRC, 2013). For those US stocks assessed using analytical methods, fishing mortality under rebuilding plans has generally been reduced and stock biomass has generally increased following the introduction of the MSFCMA and the associated MSYbased management framework (NRC, 2013).

The 2008 SPA-based assessment of the Gulf of Maine cod stock estimated that the biomass was increasing and that the stock was no longer Overfished although Overfishing was still occurring (NEFSC, 2008; Pershing et al., 2013). A 2008 independent assessment by industry consultants using SCAA was even more optimistic, estimating that $S S B$ was $1.4 * S S B_{\text {msy }}$ and that $F$ was $0.4 * F_{\text {msy }}$ (Butterworth and Rademeyer, MS 2008b). The 2011 NEFSC assessment of Gulf of Maine cod, which was based on ASAP and a new treatment of discard data, gave a much more pessimistic outcome, finding that the stock was still Overfished and that the biomass was much lower than the 2008 assessment estimate (NEFSC, 2012). Although substantial TAC reductions are required under the adopted $75 \% F_{\text {msy }}$ HCR to achieve rebuilding of Gulf of Maine cod within 10 years, full implementation of this HCR has been delayed by social, economic and political considerations. The adjacent Georges Bank cod stock was estimated to be at is only $7 \%$ of $S S B_{\text {msy }}$ in 2011 with fishing mortality more than twice $F_{\text {msy }}$ (NEFC, 2013a), suggesting difficulty in implementing the $75 \% F_{\text {msy }} \mathrm{HCR}$ on this stock as well, and therefore poor prospects for rebuilding in the near future.

In comparison with the North West Atlantic, the North East Atlantic cod landings have been maintained around one 
million tons from 2000 onwards and have even increased slightly since 2007 following the implementation of MSYbased management frameworks. The major contributors are the Barents Sea Cod and the Icelandic cod. These two stocks are the only inarguably sustainably managed Atlantic cod fisheries - Overfishing is not occurring, they are not Overfished, and they have management plans currently being implemented that include feedback HCRs to moderate $F$ below $F_{\text {msy }}$ when $S S B$ falls below $S S B_{\text {ref. }}$ These management plans have been evaluated by ICES and found to meet MSY and PA objectives. They serve as examples of the potential to rebuild and sustainably manage Atlantic cod stocks under MSY-based frameworks, although with the caveat that the historic levels of depletion of these two stocks was less severe than for a number of other Atlantic cod stocks that currently remain depleted.

Fishing mortality on Celtic Sea cod has been declining since 2005 and is now at $F_{\text {msy }}$ and $S S B$ has recently increased to well above $S S B_{\text {ref }}$ (MSY $B_{\text {trigger }}$ ). A management plan including an HCR is under development for this stock. Management of four other European cod stocks was recently reviewed by Kraak et al. (2013): Kattegat, North Sea, Irish Sea and West of Scotland cod. Three of these stocks (North Sea, Irish Sea and West of Scotland) are Overfished and Overfishing is taking place. The current status of Kattegat cod is uncertain and ICES advice is that there be no fishing under the assumption that it is severely depleted. These four stocks have HCRs in place and these have been evaluated through MSE. Inadequate implementation and enforcement of the management plans appear to be major problems in current efforts to reduce fishing mortality and rebuild these stocks (Kraak et al., 2013). Problems include basing the HCR on landings and not catch including discards, and ongoing bycatch of cod in mixed species fisheries. Kraak et al. (2013) argue that it is not sufficient to simply put an HCR in place based on MSY reference points and expect the stock to recover, particularly in the case of mixed species fisheries. Socioeconomic considerations need to be taken into account and innovative approaches need to be found that encourage stakeholders to find ways of achieving the reductions in fishing mortality required to rebuild cod stocks.

The East Baltic and West Baltic cod stocks are both above their $S S B_{\text {ref }}$ levels and therefore not Overfished and step-wise reductions in $F$ have led to a cessation in Overfishing in the case of East Baltic cod but not West Baltic cod. Recovery of the East Baltic cod is attributed to a combination of a substantial reduction in $F$ by ensuring that the TAC corresponds to fishery removals and not only landings, and strong year-classes entering the fishery (Eero et al., 2012). In contrast there has not been a similar improvement in recruitment in West Baltic cod.
Strong year-classes in combination with a reduction in $F$ under an HCR are important ingredients associated with successful rebuilding. Strong recruitment is more likely for cod stocks that have not been depleted to very low $S S B$ levels.

A major EU-funded project, aimed at producing a rational scientific basis for developing recovery strategies, undertaken between 2006 and 2010 (UNCOVER), identified a number of predictors for successful rebuilding (Hammer et al., 2010a). These include a rapid reduction in fishing mortality when depletion is first detected, favorable environmental conditions for recruitment, growth and survival during the recovery period, lifehistory characteristics conducive to stock rebuilding (e.g. size-at-maturity, maximum size, longevity, growth rate, and natural mortality), and effective management. Although the likelihood of these positive factors cooccurring may be less than desired, an international symposium marking the conclusion of the UNCOVER project jointly sponsored by ICES, PISCES and NAFO brought forward overwhelming evidence from Europe and around the world that collapsed and severely depleted fish stocks can recover and be rebuilt if fishing mortality is rapidly and substantially reduced (Hammer et al., 2010b; Murawski, 2010). However, the recovery process might be slower than predicted, especially if evolutionary changes in fish populations and ecosystem shifts have taken place that are not adequately accounted for in the assessment models (Hammer et al., 2010b). In retrospect the WSSD resolution may have been more realistic and effective had it called for an end to Overfishing by 2015 rather than setting recovery to $S S B_{\text {msy }}$ as the goal.

It is widely recognized that current MSY-based frameworks are not the last word in sustainable fisheries management because they ignore important ecosystem dynamics and environmental processes that result in variable production in the target stock (Morgan et al., 2014; Haltuch et al., 2009; Walters et al., 2005). Nevertheless, for many stocks Overfishing is the paramount reason for depletion and continuing lack of recovery, and reducing fishing mortality has to be a management priority. Getting $F$ down to the long-term $F_{\text {msy }}$ level expressed in MSY-based frameworks would be a major achievement for many of these Overfished stocks where Overfishing is continuing to occur. However, it may not be sufficient. Changes in the productivity of fish stocks caused by variability in the environment and ecosystem processes suggest it may be more desirable to consider the long-term $F_{\text {msy }}$ as a limit not to be exceeded by some chosen probability level rather than treating $F_{\text {msy }}$ as a target to be achieved with a $50 \%$ probability. For MSY-based management frameworks to be internally consistent, it would follow that $S S B_{\text {msy }}$ should, on average, be exceeded by a probability $>50 \%$. 
Consideration should also be given to rapidly reducing $F$ if a stock has fallen below $S S B_{\text {msy }}$, rather than waiting for the stock to fall to an even lower biomass corresponding to $S S B_{\text {ref }}$ before initiating a reduction in $F$. This may be particularly important in TAC-based management systems where there is an excess in fishing capacity, uncertainty in the assessment and a lag between the latest assessment of the status of the stock and the implementation in a reduction in $F$.

Atlantic cod fisheries are historically among the most important in the world. While existing MSY-based management frameworks that are universally proposed for the provision of scientific advice and management of Atlantic cod stocks may not be perfect, and may not be able to fully meet the aspirations of an ecosystem approach to fisheries management, the failure to complete these frameworks and successfully implement them in the actual management of cod fisheries, represents a major shortcoming in achieving sustainable fisheries management objectives.

\section{Acknowledgements}

The authors would like to thank Andy Payne for helpful comments on an earlier version of this manuscript as well as John Casey and an anonymous reviewer. Part of the content of this paper was initially presented as an invited key-note address at the Gadoid Fisheries Symposium, held 15-18 October 2013 in St. Andrews, New Brunswick, Canada, jointly sponsored by ICES and NAFO.

\section{References}

BEARE, D. J., C. NEEDLE, F. BURNS, and D. G. REID. 2005. Using survey data independently from commercial data in stock assessment: an example using haddock in ICES Division VIa. ICES J. Mar. Sci., 62: 996-1005. doi:10.1016/j.icesjms.2005.03.003

BUTTERWORTH, D. S., and R. A. RADEMEYER. 2008a. Statistical catch-at-age analysis vs. ADAPT-VPA: the case of Gulf of Maine cod. ICES J. Mar. Sci., 65: 1717-1732. doi:10.1093/icesjms/fsn 178

BUTTERWORTH, D. S., and R. A. RADEMEYER. MS 2008b. Further SCAA/ASPM assessments of Gulf of Maine Cod including data for 2007 and exploring the impact of agedependence in natural mortality. Groundfish Assessment Review Meeting, Woods Hole, MA Working Paper 1.F.b, 17 p. http://www.nefsc.noaa.gov/GARM-Public/4.\%20 Final\%20Assessment\%20Meeting/for\%20review/WP\%20 1.F.b.\%20GoM\%20Cod.pdf

DARBY, C. D., and S. FLATMAN. 1994. Virtual Population Analysis: Version 3.1 (Windows/DOS) User Guide. Information Technology Series, No. 1. MAFF, Directorate of Fisheries Research, Lowestoft, 85 p.

DE OLIVEIRA, J. A., L. T. KELL, A. E. PUNT, B. A. ROEL, and D.S. BUTTERWORTH. 2008. Managing without best predictions: the management strategy evaluation framework. In: Advances in Fisheries Science. 50 Years on from Beverton and Holt, p. 104 -134. A. Payne, J. Cotter, and T. Potter (eds.). Blackwell Publishing, Oxford. $\mathrm{xxi}+546 \mathrm{p}$.

DFO. 2009a. Sustainable Fisheries Framework. http://www.dfo-mpo.gc.ca/fm-gp/peches-fisheries/ fish-ren-peche/sff-cpd/overview-cadre-eng.htm

DFO. 2009b. Assessment of Cod in the Southern Gulf of St. Lawrence. DFO Can. Sci. Advis. Sec. Sci. Advis. Rep. 2009/007, 15 p. http://www.dfo-mpo.gc.ca/ CSAS/Csas/Publications/SAR-AS/2009/2009_007_e.pdf

DFO. 2009c. Cod on the Southern Scotian Shelf and in the Bay of Fundy (Div. 4X/5Y). DFO Can. Sci. Advis. Sec. Sci. Advis. Rep. 2009/015, 10 p. http://www.dfo-mpo.gc.ca/ CSAS/Csas/Publications/SAR-AS/2009/2009_015_e.pdf

DFO. 2012a. Stock Assessment of NAFO Subdivision 3Ps Cod. DFO Can. Sci. Advis. Sec. Sci. Advis. Rep. 2012/078, 19 p. http://www.dfo-mpo.gc.ca/csas-sccs/Publications/ SAR-AS/2012/2012_078-eng.pdf

DFO. 2012b. Assessment of the northern Gulf of St. Lawrence (3Pn, 4RS) cod stock in 2011. DFO Can. Sci. Advis. Sec. Sci. Advis. Rep. 2012/005, 14 p. http://www.dfo-mpo. gc.ca/csas-sccs/Publications/SAR-AS/2012/2012_005eng.pdf

DFO. 2013. Stock Assessment of Northern (2J3KL) Cod in 2013. DFO Can. Sci. Advis. Sec. Sci. Advis. Rep. 2013/014, 27 p. http://www.dfo-mpo.gc.ca/csas-sccs/Publications/ SAR-AS/2013/2013_014-eng.pdf

EERO, M. E., F. W. KöSTER, and M. Vinther. 2012. Why is the Eastern Baltic cod recovering? Mar. Pol., 36: 235-240. doi:10.1016/j.marpol.2011.05.010

FAO. 2013. Fishery Statistical Collections Global Capture Production. http:/www.fao.org/fishery/statistics/globalcapture-production/en

FOURNIER, D., and C. P. ARCHIBALD. 1982. A general theory for analyzing catch at age data. Can. J. of Fish. Aquat. Sci., 39:1195-1207. doi: 10.1139/f82-157

GAVARIS, S., MS 1988. An adaptive framework for the estimation of population size. CAFSAC Res. Doc. 88/129. Available on request in digital form from csas-sccs@ dfo-mpo.gc.ca

GONZÁLEZ-TRONCOSO, D., C. HVINGEL, B. HEALEY, J. MORGAN, F. GONZÁLEZ-COSTAS, R. ALPOIM, J-C. MAHÉ, and A. VÁZQUEZ. MS 2013. Assessment of the Cod Stock in NAFO Division 3M. NAFO SCR Doc., No. 41, Serial No. N6196, 42 p. https://archive.nafo.int/ open/sc/2013/scr13-041.pdf

GUDMUNDSSON G. 1994. Time series analysis of catchat-age observations. Applied Statistics 43: 117-126. doi:10.1016/0167-6687(94)90696-3

HaltuCH, M., A. E. PUNT, and M. A. Dorn. 2009. Evaluating the estimation of management reference points in a variable environment. Fish. Res., 100: 42-56. doi:10.1016/j.fishres.2009.03.001

HAMMER, C., C. VON DORRIEN, C. C. E HOPKINS, F. W. KÖSTER, E. M. NILSSEN, M. ST JOHN, and D. C. WILSON. 2010a. Framework of stock-recovery strategies: analyses of factors affecting success and failure. ICES J. 
Mar. Sci., 67: 1849-1855. doi: 10.1093/icesjms/fsq122

HAMMER, C., O. S. KJESBU, G. H. KRUSE, and P. A. SHELTON. 2010b. Rebuilding depleted fish stocks: biology, ecology, social science, and management strategies. ICES J. Mar. Sci., 67: 1825-1829. doi:10.1093/ icesjms/fsq039

ICES. 2009. Report of the Ad hoc Group on Icelandic Cod HCR Evaluation (AGICOD), 24-26 November 2009 ICES, Copenhagen, Denmark. ICES CM 2009\ACOM:56, 89p.

ICES. 2013. Latest advice. http://www.ices.dk/community/ advisory-process/Pages/Latest-Advice.aspx

KRAAK, S. B. M., N. BAILEY, C, M. CARDINALE, C. DARBY, J. A. A. DE OliveirA, M. EERO, N. GRAHAM, S. HOLMES, T. JAKOBSEN, A. KEMFP, E. KIRKEGAARD, J. POWELL, R. D. SCOTT, E. J. SIMMONDS, C. ULRICH, W. VANHEE, and M. VINTHER. 2013. Lessons for fisheries management from the EU cod recovery plan. Mar. Pol., 37 :200-213. doi:10.1016/j.marpol.2012.05.002

LASSEN, H., C. KELLY, and M. SISSENWINE. 2013. ICES advisory framework 1977-2012: from $F_{\max }$ to precautionary approach and beyond. ICES J. Mar. Sci., 71: 166-172. doi:10.1093/icesjms/fst146

MORGAN, M. J., P. A. SHELTON, and R. M. RIDEOUT. 2014. Varying components of productivity and their impact on fishing mortality reference points for Grand Bank Atlantic cod and American plaice. Fish. Res., 155: 64-73 doi: 10.1016/j.fishres.2014.02.019.

MURAWSKI, S. A. 2010. Rebuilding depleted fish stocks: the good, the bad, and, mostly, the ugly. ICES J. Mar. Sci., 67: 1830-1840. doi:10.1093/icesjms/fsq125

NAFO. 2004a. NAFO Precautionary Framework. NAFO/FC Doc. 04/18, 5 p. http://www.nafo.int/science/research/ docs/fcdoc04-18.pdf

NAFO. 2004b. Report of the NAFO Study Group on Limit Reference Points Lorient, France, 15-20 April, 2004. NAFO SCS Doc. 04/12, 72 p. http://archive.nafo.int/open/sc/2004/scs04-012.pdf

NAFO. 2008. Resolution on the Interpretation and Implementation of the Convention on the Future Multilateral Cooperation in the Northwest Atlantic Fisheries. NAFO/GC Doc. 08/3, 1 p. http:// archive.nafo.int/open/gc/2008/gcdoc08-03.pdf

NAFO. 2013. Report of the NAFO Scientific Council June Meeting - 2013. NAFO SCS Doc. 13/17, 252 p. http://archive.nafo.int/open/sc/2013/scs13-17.pdf

NEFSC. 2008. Assessment of 19 Northeast Groundfish Stocks through 2007: Report of the $3^{\text {rd }}$ Groundfish Assessment Review Meeting (GARM III), Northeast Fisheries Science Center, Woods Hole, Massachusetts, August 4-8, 2008. USA Department of Commerce, NOAA Fisheries, Northeast Fisheries Science Center Reference Document, 08-15, 884 pp + xvii. http://www.nefsc.noaa. gov/publications/crd/crd0815/

NEFSC. 2012. 53 ${ }^{\text {rd }}$ Northeast Regional Stock Assessment Workshop (53 ${ }^{\text {rd }}$ SAW) Assessment Report. US Department of Commerce, NOAA Fisheries, Northeast Fisheries Science Center Reference Document, 12-05,
559 p. http://www.nefsc.noaa.gov/publications/crd/crd1205/ NEFSC. 2013a. 55 ${ }^{\text {th }}$ Northeast Regional Stock Assessment Workshop ( $55^{\text {th }}$ SAW) Assessment Summary Report. US Department of Commerce, NOAA Fisheries, Northeast Fisheries Science Center Reference Document, 13-01, 41 pp. http:// www.nefsc.noaa.gov/saw/saw 5 5/crd 1301 .pdf

NEFSC. 2013b. National Marine Fisheries Service - NOAA Fisheries Toolbox - Age Structured Assessment Program (ASAP). https://www.nefsc.noaa.gov/nft/ NOAA. 2007. Magnuson - Stevens Fishery Conservation and Management Act. Public Law 94-265 as amended by the Magnuson - Stevens Fishery Conservation and Management Reauthorization Act (P.L. 109-479). National Oceanic and Atmospheric Administration, Silver Spring, MD, USA, 176 p. http:/www.nmfs.noaa.gov/msa2005/ docs/MSA_amended_msa\%20_20070112_FINAL.pdf NRC. 2013. Evaluating the Effectiveness of Fish Stock Rebuilding Plans in the United States. Report of the Committee on Evaluating the Effectiveness of Stock Rebuilding Plans of the 2006 Fishery Conservation and Management Reauthorization Act. National Research Council. National Academies Press, 282 p. http://www. nap.edu/catalog.php?record_id=18488

PERSHING, A. J., J. H. ANNALA, S. EAYRS, L. A. KERR, J. LABAREE, J. LEVIN, K. E. MILLS, J. A. RUNGE, G. D. SHERWOOD, J. C. SUN, and S. T. CAPOROSSI. 2013. The future of Gulf of Maine Cod. Gulf of Maine Research Institute, 15 p. http://gmri.org/upload/files/GMRI\%20 -\%20The $\% 20$ Future $\% 20$ of $\% 20$ Cod $\% 20$ in $\% 20$ the $\% 20$ Gulf $\% 20$ of $\% 20$ Maine.pdf

SHELTON, P. A., and M. J. MORGAN. 2005. Is by-catch mortality preventing the rebuilding of cod (Gadus morhua) and American Plaice (Hippoglossoides platessoides) stocks on the Grand Bank? J. Northw. Atl. Fish. Sci., 36: 1-17. doi:10.2960/J.v36.m544

SHELTON, P. A., A. F. SINCLAIR, G. A. CHOUINARD, R. MOHN, and D. E. DUPLISEA. 2006. Fishing under low productivity conditions is further delaying recovery of Northwest Atlantic cod (Gadus morhua). Can. J. Fish. Aquat. Sci., 63: 235-238. doi:10.1139/f05-253

STARR, P., J. H. ANNALA, and R. HILBORN, R. 1998. Contested stock assessment: two case studies. Can. J. Fish. Aquat. Sci., 55: 529-537. doi: 10.1139/f97-230

SHEPHERD, J. G. 1999. Extended survivors analysis: an improved method for the analysis of catch-at-age data and abundance indices. ICES J. Mar. Sci., 56: 584-591. doi:10.1006/jmsc. 1999.0498

SWAIN, D. P. and G. A. CHOUINARD. 2008. Predicted extirpation of the dominant demersal fish in a large marine ecosystem: Atlantic cod (Gadus morhua) in the southern Gulf of St. Lawrence. Can. J. Fish. Aquat. Sci., 65: 2315-2319. doi:10.1139/F08-175

UN. 1995. Agreement for the Implementation of the Provisions of the United Nations Convention on the Law of the Sea of 10 December 1982 Relating to the Conservation and Management of Straddling Fish Stocks and Highly Migratory Fish Stocks. http://www.un.org/depts/los/ 
SHELTON and MORGAN: Impact of fisheries management on rebuilding North Atlantic cod stocks

convention_agreements/texts/fish_stocks_agreement/ CONF164 37.htm

UN. 2002. Report of the World Summit on Sustainable Development, Johannesburg, South Africa, 26 August-4 September. Chapter I. Resolutions adopted by the Summit. 2. Plan of Johannesburg Plan of Implementation of the World Summit on Sustainable Development, IV. Protecting and managing the natural resource base of economic and social development, Paragraph 31. https://selectra.co.uk/ sites/selectra.co.uk/files/pdf/WSSD_PlanImpl.pdf

WALTERS, C. J., V. CHRISTENSEN, S. MARTELL, and J. F. KITCHELL. 2005. Possible ecosystem impacts of applying MSY policies from single-species assessment. ICES J. Mar. Sci., 62: 558-568. doi:10.1016/j.icesjms.2004.12.005 
